Research Article

\title{
Partitioning Control Mechanism and Engineering Practice of Rebuilding Bearing Arch in Surrounding Rock under High Ground Stress
}

\author{
Mengtang $X u\left(\mathbb{D},{ }^{1} \operatorname{Ke~} L i \mathbb{D}^{1,2}\right.$ and Youlin $X u^{1}$ \\ ${ }^{1}$ College of Mining, Guizhou Institute of Technology, Guiyang, Guizhou 550003, China \\ ${ }^{2}$ School of Resource \& Environment and Safety Engineering, Hunan University of Science and Technology, Xiangtan, \\ Hunan 411201, China
}

Correspondence should be addressed to Ke Li; 20120016@git.edu.cn

Received 3 December 2020; Revised 6 January 2021; Accepted 12 January 2021; Published 19 January 2021

Academic Editor: Xianjie Hao

Copyright (C) 2021 Mengtang Xu et al. This is an open access article distributed under the Creative Commons Attribution License, which permits unrestricted use, distribution, and reproduction in any medium, provided the original work is properly cited.

\begin{abstract}
The mining of coal seam has a significant influence on the stability of the roadway near it, especially under the condition of high ground stress. To study the control mechanism of the surrounding rock under the influence of high ground stress, a general idea for the partition control of the rebuilding bearing arch (RBA) was proposed in this paper. Based on the basic mechanical performance test of the bearing arch, this paper built a mechanical model of the RBA based on Protodyakonov's pressure arch theory, analyzed the influence of the strength of the bearing arch on the surrounding rock failure, and obtained the ultimate thickness of the bearing arch failure under high ground stress. The results show that the RBA's damage is closely related to the overburden load and RBA's thickness. The tensile stress and shear stress of RBA increase linearly with the overburden load increase and increase sharply with the load-bearing arch's thickness, showing a nonlinear relationship. To maintain the surrounding rock's stability, it is necessary to ensure that the RBA's thickness is within a specific range. The results are applied to the Wantian coal mine. The theoretically determined load-bearing thickness is $10 \mathrm{~m}$, which can effectively control the surrounding rock deformation and significantly reduce the roadway's repair rate.
\end{abstract}

\section{Introduction}

The problem of surrounding rock control of roadways under the influence of high ground stress has always been problematic in underground mine engineering. Especially in multi-coal mining, the roadways near the coal seams are affected by high ground stress, and the problem of nonlinear considerable deformation control is particularly prominent $[1,2]$. Under the influence of high ground stress, the surrounding rock's stress environment has deteriorated, and the surrounding rock is easy to show a nonlinear and uneven massive deformation phenomenon. The roadway support structure's stability is reduced, and the repair rate is significantly increased $[3,4]$. It is not easy to control the continuous deformation of roadway surrounding rock only by strengthening conventional support. Improving the structure and mechanical properties of the surrounding rock is the fundamental way to control roadway deformation surrounding rock [5]. Rebuilding the bearing arch through grouting can effectively improve the bearing capacity of the surrounding rock of the roadway, leave a pressure relief space for high ground stress, and decompose and alleviate the impact of mining stress. For roadways affected by high ground stress, proper grouting to save material costs while ensuring the grouting effect and improving the surrounding rock's self-carrying capacity has become an urgent problem in controlling the roadway's surrounding rock $[6,7]$. Therefore, it has important theoretical significance and engineering practical value to study the control mechanism of RBA of the surrounding rock affected by high ground stress. 
Some scholars have done some sufficient research work on the surrounding rock control theory and the highpressure roadway technology in recent years. Meng et al. $[8,9]$ studied the displacement, plastic zone, and distribution law of principal stress difference with different support schemes under the influence of mining disturbance on the bottom extraction roadway and proposed a U-shaped steel reinforced support scheme. Wang et al. [10] found that the width of excavation damaged zone around roadways under dynamic pressure was larger than that under static pressure, and they proposed that the bolt length should be larger than the width of excavation damaged zone. Tian and Gao [11] established a mechanical model of adjacent rock strength, mining stress, and supporting resistance based on an elastic-plastic theory of mechanics, and they obtained an analytical solution for stress and displacement distribution of elastic and plastic regions in surrounding rock of dynamic pressure roadway. Yan and He [12] proposed a new cable truss support system for coal roadways affected by dynamic pressure, established a theoretical formula for the pretightening force required for the truss cables, and deduced the lowest anchoring force between the roof surrounding rock and the cable bolt. Wang et al. [13] put forward a dynamic pressure roadway supporting scheme under the surrounding rock condition and stress environment and proved that the length of small aperture cable hole has a more significant impact on anchoring effect. Zhang et al. [14] analyzed the asymmetry characteristics of surrounding rock structure and stress distribution in dynamic pressure roadway and proposed an asymmetrical support scheme. Yang et al. [15] examined the technology of directional fracturing blasting for pressure relief of dynamic pressure roadway. Zuo et al. $[16,17]$ theoretically derived the Hoek-Brown rock failure criterion based on the linear elastic fracture theory and established the analogous hyperbola movement model of overlying strata. Wu et al. $[18,19]$ proposed an improved support scheme for the roadway in steeply inclined geological formations. Zhang et al. [20] studied the change laws of the maximum principal stress and the minimum one for the floor roadway surrounding rock when mining the upper working face, and they built the mechanical model of roadway stress based on the nonconstant pressure force state and the cracks revolution mechanisms of floor roadway surrounding rock. Xie et al. [21, 22] deduced the equation of maximum shear stress in the deep beam structure based on the stress superposition criterion. Zhang et al. [23-25] investigated the lower coal seam entry failure mechanism's characteristics under the remnant pillar by means of numerical simulations and in situ observations. Yu et al. [5, 26-29] established the mechanical model of overlap arch bearing body in allusion to the united supporting characteristics of anchor, spray net, and cable bolt of deep wall rock, which are composed of the main compression arch (bolt supporting) and the second compression arch (intensive cable bolt supporting), and deduced neutral point theory of bolt and force transferring mechanism of cable bolt, strength equations of the bearing body of primary supporting and second supporting. Huang et al. [30] proposed the concept of strong mining and large deformation of roadway from mechanical essence and engineering application, established the quantitative evaluation method of intense mining and large deformation, and considered that the large deformation of the surrounding rock structure of the roadway includes the large deformation of the whole movement caused by the large structure instability of the overlying strata and the large deformation of the movement of the fractured rock mass in the loosening circle. Zhu et al. [31] established the roadway's numerical model by combining the results of exploration test, microproperties calibration, tension and shear test of rock bolt, and bearing characteristics of timber. Yang et al. [32, 33] proposed a support technology focusing on cutting off the water, strengthening the rock's small structure, and transferring its immense structure.

However, due to the complexity and difference of the geological environment and production conditions in deep coal seam mining, the instability and control problems of deep dynamic pressure mining roadways have not been completely solved. The deformation and failure mechanism of the surrounding rock under the influence of high ground stress needs to be further studied. [34, 35]. Based on Protodyakonov's pressure arch theory and field investigation and analysis, this paper establishes a mechanical model for reconstructing the bearing arch of the roadway's surrounding rock under high ground stress conditions. The ultimate thickness of failure provides a scientific basis for controlling surrounding rock in this type of roadway.

\section{Research Engineering Background}

2.1. The Condition of the Roadway Studied. This paper is based on the engineering background of the crossheading 1433 restoration project of Wantian coal mine, Panzhou city, Guizhou Province, China. Its depth is about $820 \mathrm{~m}$. The surrounding rock of crossheading 1433 is dominated by mudstone and siltstone, and overlying 10\#, 12\#, 15\#, 17\#, and 18\# coal seam. The crossheading is affected by high ground stress, causing large deformation and severe damage. After many repairs, the effect gets worse with the repair. The damage of the crossheading supporting structure is shown in Figure 1.

The roadway damage characteristics affected by high ground stress are considerable damage depth, high damage degree, and lacking integrity of surrounding rock. In recent years, the original support adopts U29 U-steel support, the row spacing is $700 \mathrm{~mm}$, and the cable bolt and iron channel are used as reinforcement support. However, due to high ground stress, U-steel's damage in the roadway has become more and more serious. The maximum deformation of the sidewalls reached $2.5 \mathrm{~m}$. The severe floor heave section reached $2.7 \mathrm{~m}$ in 3 quarters, and the local roof subsidence reached $1.0 \mathrm{~m}$, which seriously affected the normal production of the mine. It could not meet the regular transportation and ventilation requirements of the roadway. It needs to be repaired 2-3 times every year. 


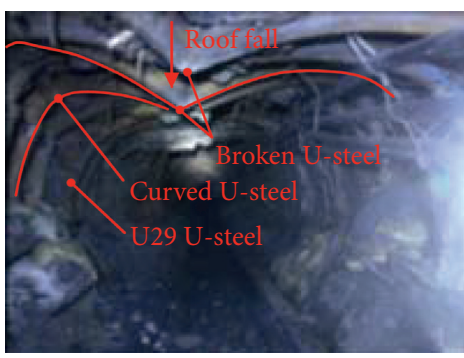

(a)

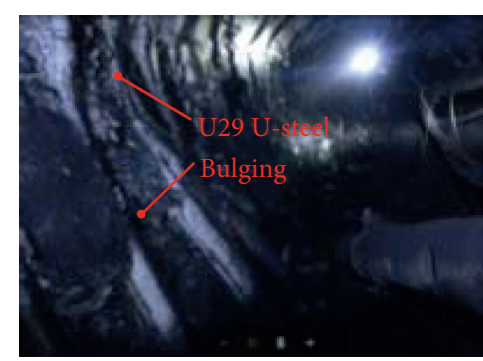

(b)

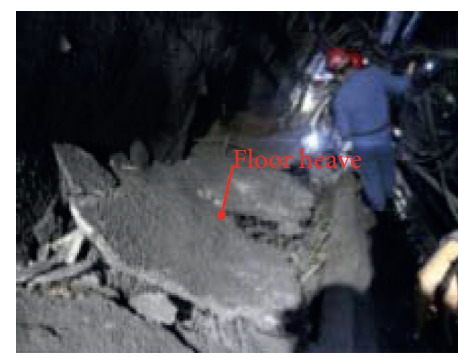

(c)

Figure 1: The damage of the crossheading supporting structure.

2.2. Stress Monitoring of Bolts and Cable Bolts. During the mining period of 11502 working face in the upper part of crossheading 1433, roof subsidence and floor heave occurred in the surrounding rock of roadway. During the mining period of the upper 11502 working face, the roof subsidence and floor heave occurred in crossheading 1433 surrounding rock. To monitor the change of bearing capacity of roadway supporting structure (bolts and cable bolts) affected by mining, SHH-60 hydraulic dynamometer was used to monitor three bolts and two cable bolts at the sidewalls, arch, and top. The monitoring time was 42 days. The stress variation curve of bolts and cable bolts is shown in Figure 2. It can be seen that, during the mining process of the working face, the load-bearing capacity of the sidewalls and arch bolts does not change much. During the monitoring period of 20-30 days, under the influence of heavy mining, the anchor cable bolt's bearing capacity increases, and the maximum bearing capacity of the bolt is $66 \mathrm{kN}$. After the end of mining, the cable bolt's stress gradually decreases and tends to be stable at $40-48 \mathrm{kN}$. Compared with the side bolt and arch bolt, the roof bolt bearing capacity is more extensive, with a maximum of $82 \mathrm{kN}$. After being affected by heavy mining, the ultimate stability value is $72-75 \mathrm{kN}$.

The anchorage depth of the cable bolt is $6.0 \mathrm{~m}$. At the initial stage of monitoring, the cable bolt load at the top and arch is $70 \mathrm{kN}$ and $56 \mathrm{kN}$, respectively. When the distance is about $30 \mathrm{~m}$ from the stoppage line, the cable bolt's bearing capacity reaches $120 \mathrm{kN}$ and $93 \mathrm{kN}$, respectively. During the upper working face's mining period, the cables' bearing capacity had not changed significantly.

Under the influence of high ground stress, the roof bolt's maximum bearing capacity is $82 \mathrm{kN}$, and the maximum bearing capacity of the top cable bolt is $126 \mathrm{kN}$. Therefore, it is difficult to restrain the continuous deformation of roadway surrounding rock only by strengthening conventional roadway support. It is imperative to improve the structure and mechanical properties of surrounding rock.

\section{General Idea of Partition Control of RBA}

Taking the support system's integrity as the basic idea, the zoning control method from the whole to the local and from the external field to the internal field is proposed. The integrity of the roadway's surrounding rock is restored by grouting the surrounding rock in the roadway's shallow part. Then, the high preload is applied to the surrounding rock to

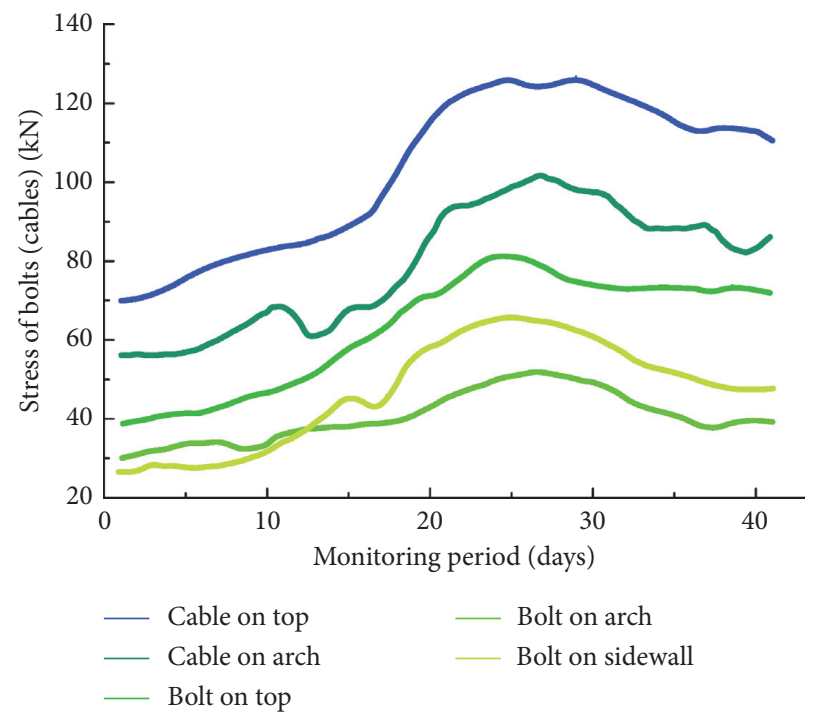

FIgURE 2: Stress variation curve of bolt and cable bolt under the influence of high ground stress.

give full play to the role of active support, so that a bearing arch "shell" with strong bearing capacity is formed in the shallow part of the surrounding rock of the roadway. The broken surrounding rock outside the bearing arch is used to decompose the upper mining stress, so that the mining stress can be digested and absorbed for the first time in the pressure relief area of the deep broken surrounding rock. The destructive force of the mining stress transferred to the surrounding rock of the roadway is reduced. The reinforced bearing arch can effectively resist the destructive force transmitted by the "digestion and absorption" of mining stress, to control the stability of surrounding rock. In the actual control process, the bearing arch's mechanical properties and the radius of the arch body are the key to the success of the zoning control. In the actual coal mine engineering, the grouting cannot be unlimited, which not only causes material waste, but also reduces the buffer effect of the broken zone, which provides a continuous path for the propagation of mining stress and leads to roadway damage.

\section{Control Mechanism of RBA}

4.1. Mechanical Properties of RBA. Through the uniaxial compression test, uniaxial tensile test, and shear test, RBA's 
mechanical parameters are obtained, which can be used to calculate the ultimate arch thickness without breaking. The grouting material is high water quick-setting material divided into material $A$ and material $B$. The ratio of material $A$ to material $\mathrm{B}$ is $1: 1$. The gangue is taken from the top of crossheading 1433. The lithology is siltstone, and the ratio of water: Ash: gangue is $1.2: 1: 1$. The uniaxial compressive strength, tensile strength, and shear strength of RBA are 8.62 $\mathrm{MPa}, 1.12 \mathrm{MPa}$, and $2.08 \mathrm{MPa}$. The experimental process is shown in Figure 3.

4.2. Mechanical Model of RBA. According to the field measurement of roadway surrounding rock deformation, the roadway surrounding fracture zone's scope increases rapidly due to high ground stress, which makes the roadway support scope increase. RBA construction around the roadway can reduce the roadway deformation and overlying roof pressure, which plays an essential role in the maintenance of roadway deformation. It is necessary to establish a new mechanical model to determine the surrounding rock pressure of the roadway. The calculation of surrounding rock pressure under the condition of loose body accords with the basic assumption of Protodyakonov's pressure arch theory. The surrounding rock pressure is calculated by Protodyakonov's pressure arch theory, as shown in Figure 4, where $Q$ is the in situ stress, $R$ is the radius of bearing arch, $a_{1}$ is the maximum span of natural balance arch, $b$ is the maximum height of natural balance arch, and $\varphi$ is internal friction angle of the rock.

Loose rock mass itself can form a natural balance arch structure, and the vertical pressure transmitted above the working face is the weight of loose rock mass in the natural balance arch. The stability of the natural balance arch under the influence of high ground stress is the core of the roadway's rock stability. The overall performance of rock mass in the natural balance arch needs to be improved.

According to Protodyakonov's pressure arch theory, the maximum span of a natural balanced arch is as follows:

$$
a 1=R+R \tan \left(45^{\circ}-\frac{\varphi}{2}\right) \text {. }
$$

The upper part of the RBA is a natural balance arch, and its height increases with the increase of the RBA height. The maximum compressive stress $q_{\max }$ in the natural equilibrium arch can be obtained as follows:

$$
q_{\max }=\frac{a 1 \gamma}{f},
$$

where $f$ is the firmness coefficient of the rock mass, and $\gamma$ is the density of rock mass.

\subsection{Tensile Failure Analysis of RBA}

4.3.1. Establishment of Tensile Failure Mechanical Model of $R B A$. The stress model of the roadway is simplified as a plane half-cylinder stress model. The semicircular arch is subjected to uniform load $q$, and both ends of the semicircular arch are constrained by simply supported beams, as shown in Figure 5, where $R$ is the radius of the arch, and $h$ is the thickness of the arch.

Considering that the arch's failure mode is caused by the semicircular arch's tensile failure, the maximum bending moment $M_{\max }$ of the semicircular arch beam needs to be solved. Because the beam's shape and force take the $y$-axis as the symmetry axis, the semicircular arch beam's bending moment also takes the $y$-axis as the symmetry axis. So, it is only needed to solve half of the solution of the semicircle arch.

If the bending moment of any angle $\alpha$ is $\mathrm{M}_{\alpha}$, as shown in Figure 6 , the calculation formula of bending moment $\mathrm{M}_{\alpha}$ can be expressed as follows:

$$
M_{\alpha}=q^{2}-q R^{2} \cos \alpha-M_{q},
$$

where $M_{q}$ is the end bending moment of overlying strata load $q$ to $\alpha$ angle.

By comparing the change of unit stress gradient $\Delta \sigma_{n, t}$, the impact risk and impact risk area can be evaluated.

Then, the expression of bending moment $M_{\alpha}$ is

$$
M_{\alpha}=-3 q R^{2}-q R^{2} \cos \alpha+4 q R^{2} \cos \left(\frac{\alpha}{2}\right)
$$

The value range of $\alpha$ is $[0, \pi / 2]$.

As the bending moment of the semicircular arch, the beam is symmetrically distributed with $\alpha=\pi / 2$, and the variation relationship of bending moment in the arch is as shown in Figure 7.

The relationship between bending moment and the angle of the semicircular arch is shown in Figure 8.

Therefore, when the angle of $\alpha$ is $\pi / 2, M_{\alpha}$ reaches the maximum value, then

$$
M q_{\max }^{2}=0.17 q R^{2}
$$

The maximum tensile stress $\sigma_{\max }$ of the semicircular arch beam can be calculated as follows:

$$
\sigma_{\max }=\frac{1.02 q R^{2}}{h} .
$$

(1) If the radius $R$ of the semicircular arch is $14 \mathrm{~m}$, the relationship between the stress of the beam and the load of the overlying strata and the arch thickness is shown in Figure 9

(2) If the arch thickness $h$ of the semicircular arch is $6 \mathrm{~m}$, the relationship between the arch's stress and the overlying strata's load and the arch radius is shown in Figure 10.

It can be seen from Figures 9 and 10 that the maximum tensile stress of semicircular arch is related to the load of overburden rock, the thickness of the arch, and the radius of semicircular arch. The maximum tensile stress increases with overburden rock load and decreases sharply with the increase of arch thickness, showing a nonlinear relationship. Therefore, it is necessary to increase the thickness of the semicircular arch to ensure that the semicircular arch does not break. 


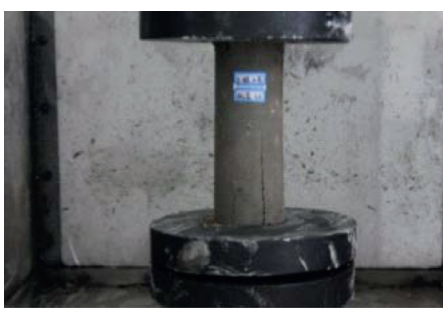

(a)

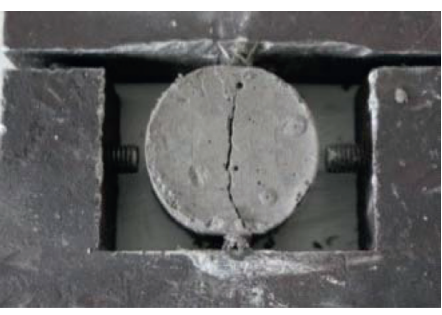

(b)

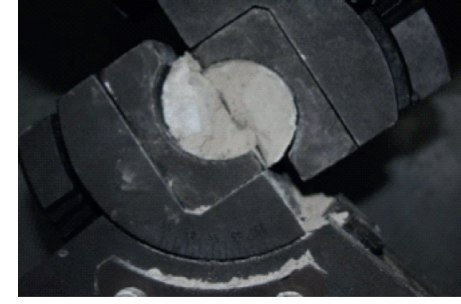

(c)

Figure 3: Experimental process of mechanical properties of RBA. (a) Uniaxial compression test. (b) Uniaxial tensile test. (c) Shear test.

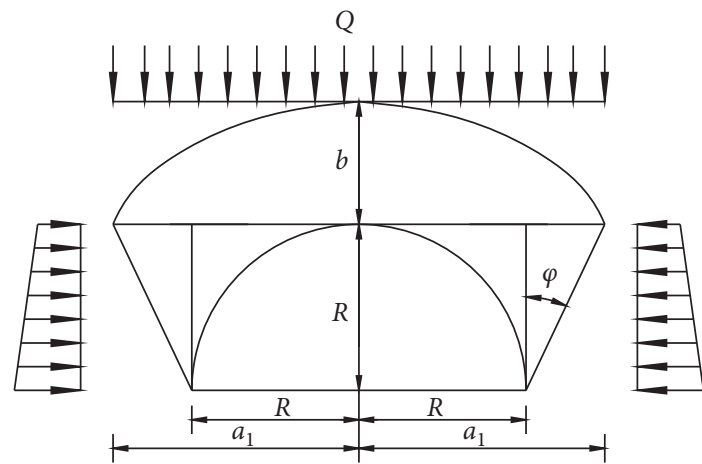

Figure 4: Mechanical model of RBA.

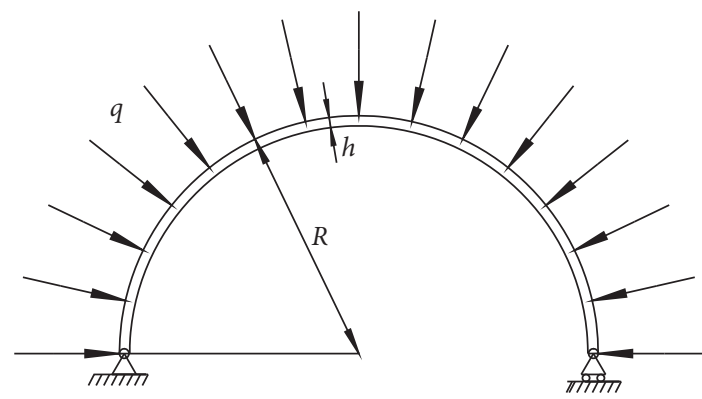

Figure 5: Simplified stress model of half-cylinder arch.

(3) The thickness of RBA

The grouting radius $r$ of crossheading 1433 is $12 \mathrm{~m}$. The stable internal friction angle and tensile strength of high water-cement are $45^{\circ}$ and $1.12 \mathrm{MPa}$, respectively. Put them into equation (2), then $\gamma \approx 2.2 \times 10^{4} \mathrm{~N} / \mathrm{m}^{3}, f=0.86$. The maximum load of overburden rock is $0.434 \mathrm{MPa}$, the dead weight of semicircular arch is $0.264 \mathrm{MPa}$, and the maximum load of the semicircular arch beam is $0.698 \mathrm{Mpa}$.

According to equation (6), the thickness of RBA must meet the following equation's requirements.

$$
h_{\text {arch }}=\sqrt{\frac{1.02 q}{\sigma_{\max }}} R=9.57 m
$$

The actual semicircular arch thickness of crossheading 1433 is $10 \mathrm{~m}$, which meets the requirements of tensile strength.

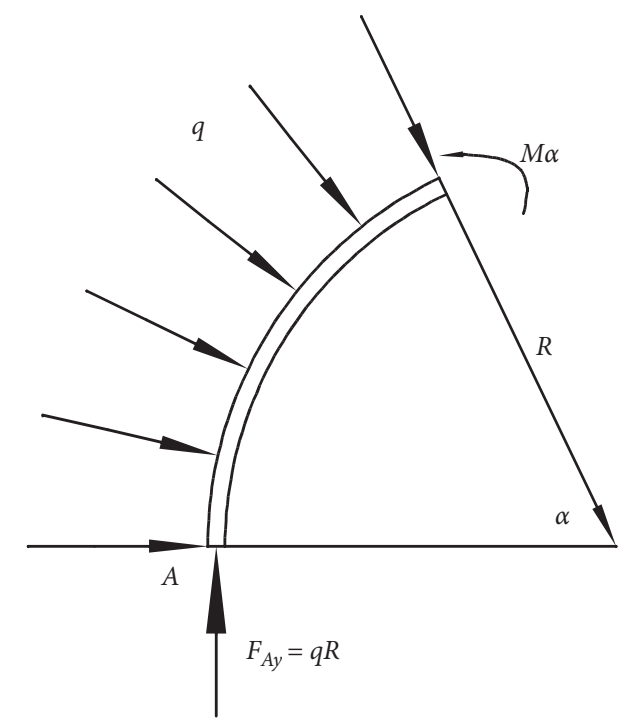

FIgURE 6: Bending moment of a semicircular arch.

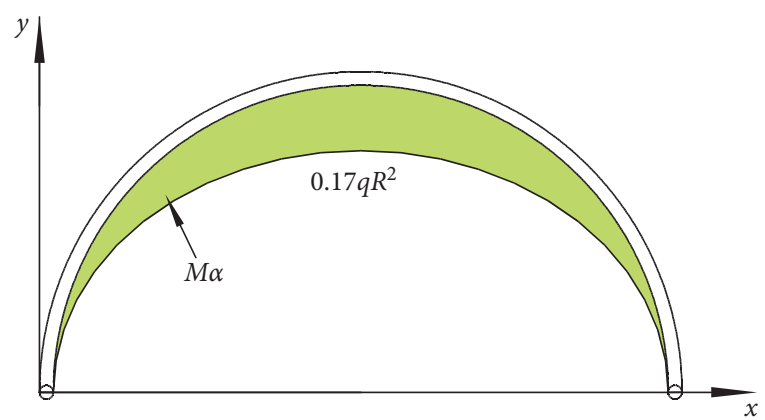

Figure 7: Bending moment of a semicircular arch.

\subsubsection{Shear Failure Analysis of RBA.}

(1) Calculation of maximum shear stress of RBA

It can be seen from the RBA stress model in Figure 4 that the shear force of the bearing arch is the largest in the middle of the semicircular arch, as shown in Figure 10. The inner radius of the circular arch is $a$. The outer radius is $b$, and the edge of the outer radius is affected by the uniformly distributed load $q$, as shown in Figure 11. 


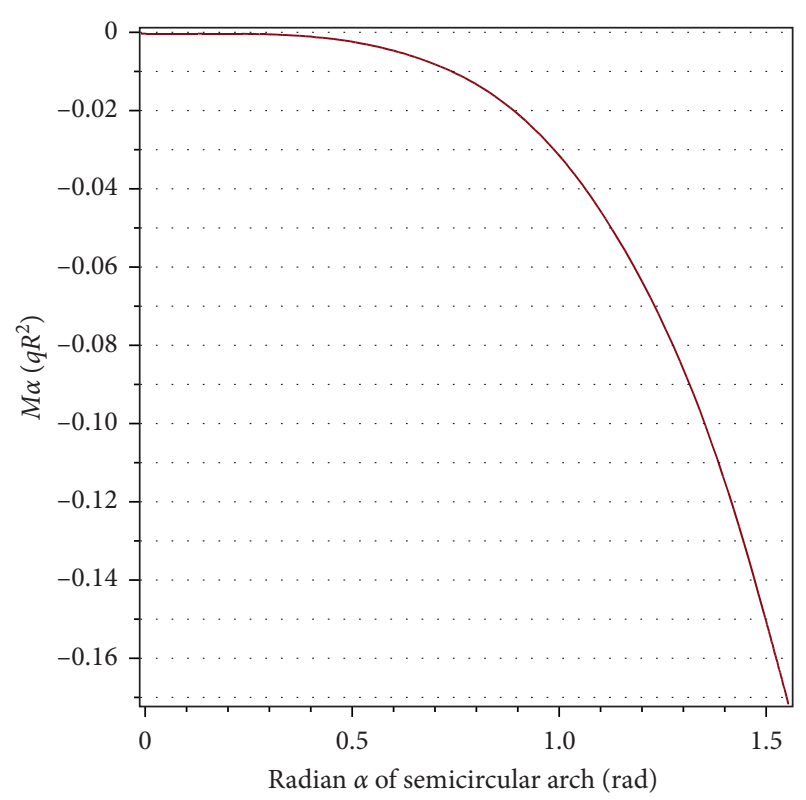

Figure 8: Relationship between bending moment and angle of a semicircular arch.

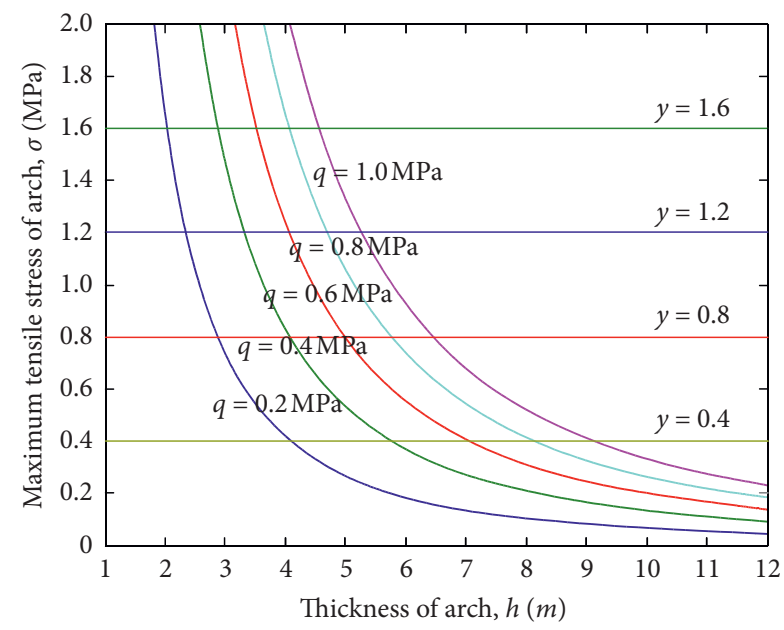

FIGURE 9: Relationship between beam stress and overburden rock layer load and arch thickness.

Therefore, the maximum shear force $F_{\text {smax }}$ can be obtained as follows:

$$
F_{\text {smax }}=\int_{0}^{(\pi / 2)} q \sin \theta R \mathrm{~d} \theta=q R .
$$

When the maximum shear stress on the rectangular section is 1.5 times of the average shear stress [36], the maximum shear stress of the semicircular arch is obtained as follows:

$$
\tau_{\max }=\frac{1.5 q R}{h} .
$$

(2) Determination of shear strength of RBA

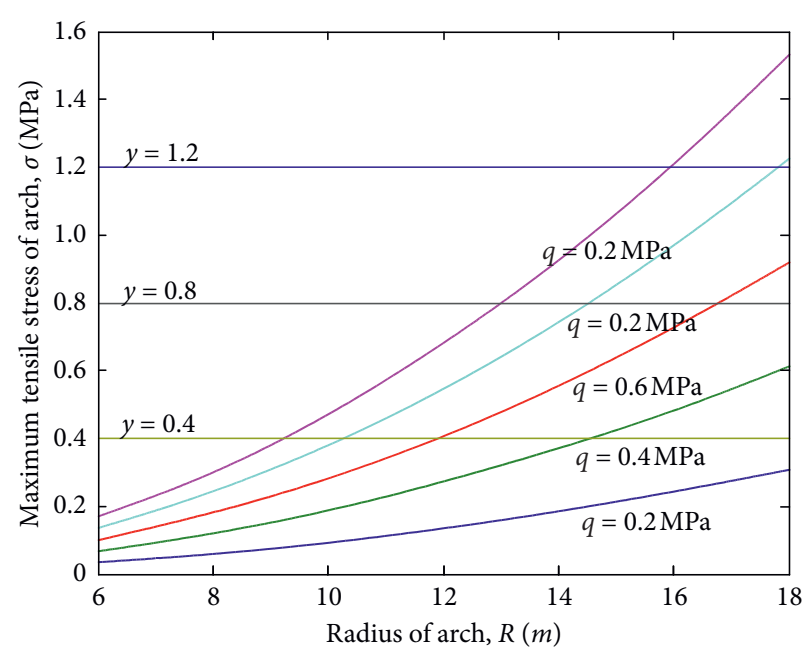

FIGURE 10: Relationship between arch stress, overburden rock load, and arch radius.

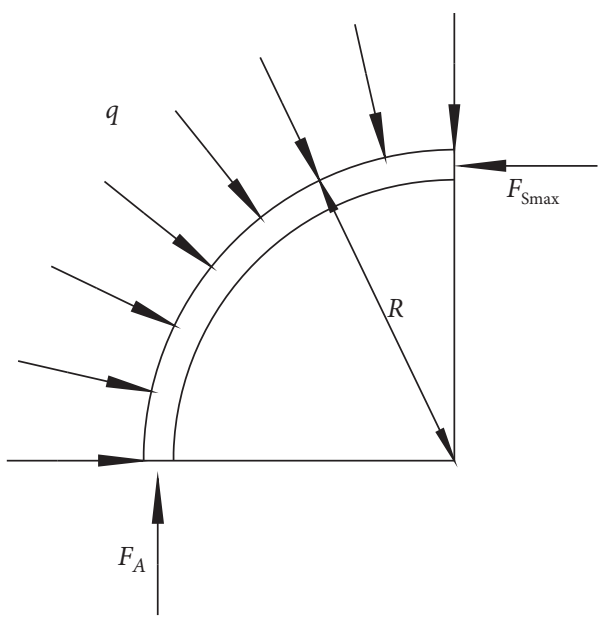

Figure 11: Maximum shear force of RBA.

The actual radius $R$ of the semicircular arch is $12 \mathrm{~m}$, the thickness $h$ is $10 \mathrm{~m}$, and the maximum load on the semicircular arch is $0.698 \mathrm{MPa}$. According to equation (9), the shear strength of the semicircular arch must meet the following requirement:

$$
\tau_{\max }=1.256 \mathrm{MPa} \text {. }
$$

The shear strength of RBA is $2.08 \mathrm{MPa}$, which meets the requirement.

\section{Engineering Practice Verification}

The RBA thickness of crossheading 1433 is determined to be $10 \mathrm{~m}$ by theoretical mechanical analysis. The field grouting industrial test was carried out in the coal mine, and the grouting material was high water material. The engineering practice shows that the actual compressive, tensile, and shear strength of the high water material and the roadway's 


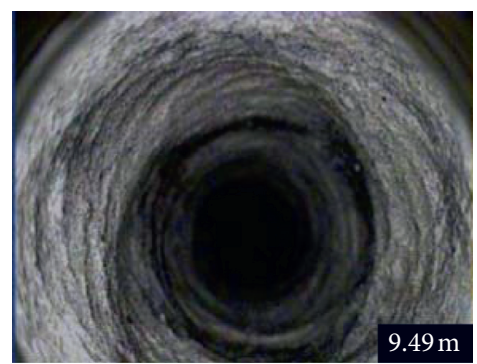

(a)

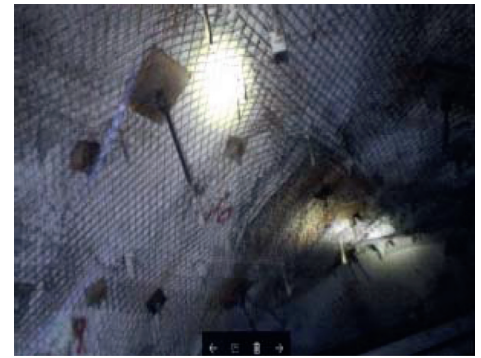

(d)

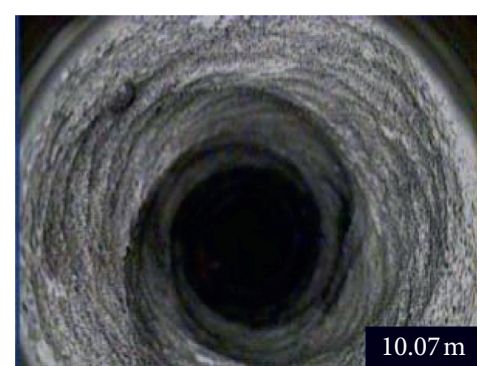

(b)

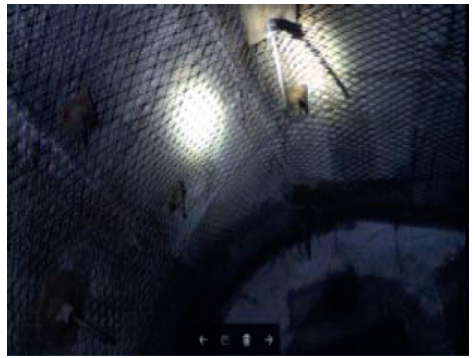

(e)

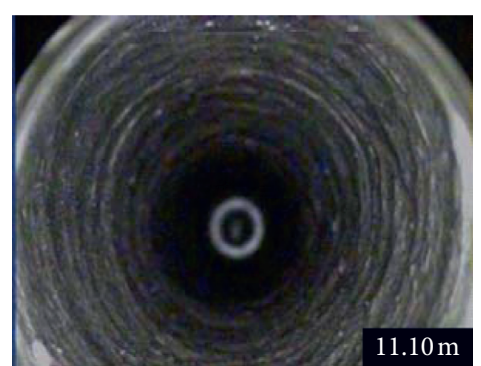

(c)

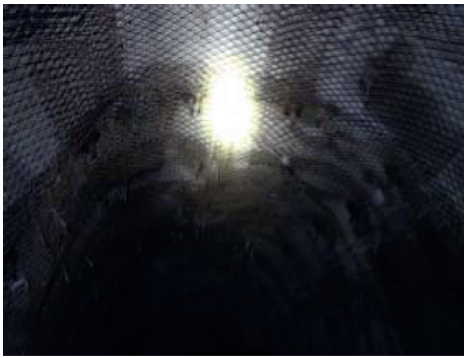

(f)

FIGURE 12: Photos of the project site after the completion of support. (a-c) Internal conditions after grouting. (d-f) Surface after grouting.

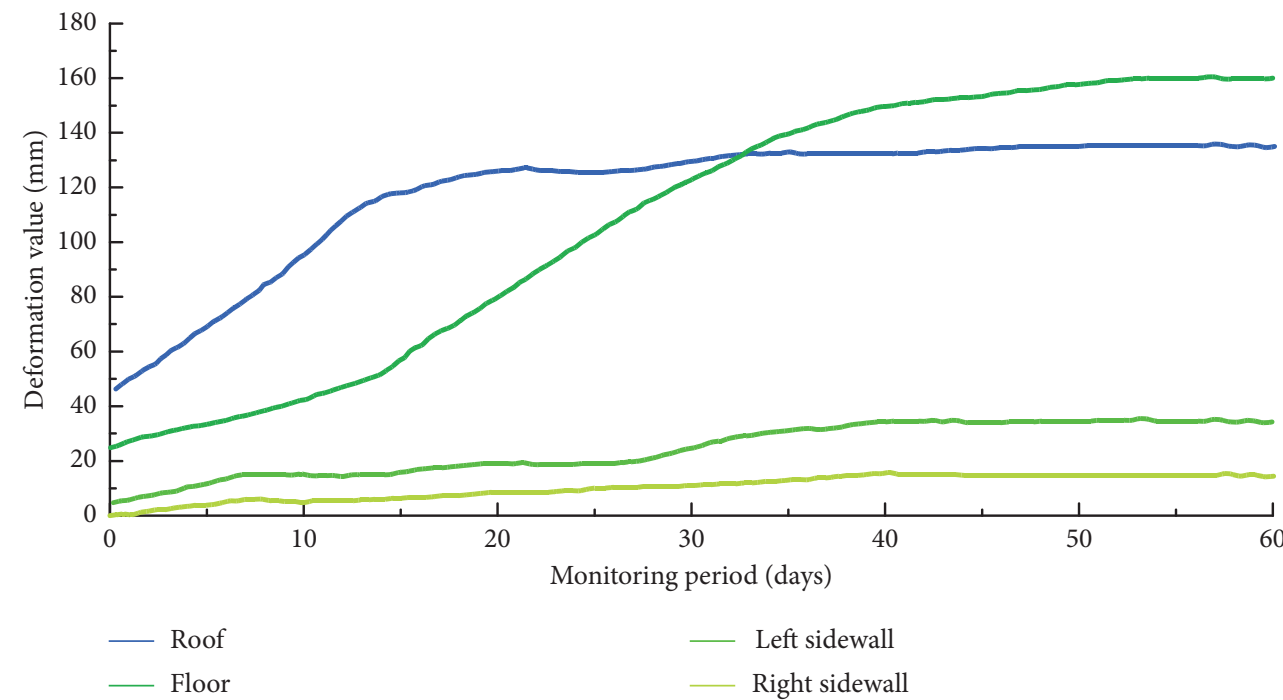

FIgURE 13: Monitoring data of roadway surface displacement after grouting.

surrounding rock cement can be calculated to meet the engineering needs. The reconstructed bearing arch can effectively control the surrounding rock deformation. The stability of surrounding rock before and after engineering practice is prominent, and the deformation of roadway surrounding rock is effectively controlled. The deformation of roadway monitored on-site is shown in Figures 12 and 13. During the monitoring period, the maximum subsidence of roadway roof is $135 \mathrm{~mm}$, and the maximum value of roadway floor heave is $160 \mathrm{~mm}$. The deformation of both sides is small, and the cumulative displacement is $30 \mathrm{~mm}$. The deformation of surrounding rock in-field measurement is significantly reduced, especially floor heave. The deformation of surrounding rock is effectively controlled, and the repair rate is significantly reduced. This proves that the RBA model established in this paper is reliable.

\section{Conclusion}

(1) Given the difficulties of surrounding rock control of roadway with considerable failure depth and high damage degree under the influence of high ground stress, the RBA zoning control method from the whole to the local and from the external field to the internal field is proposed.

(2) The mechanical model of surrounding rock pressure of "RBA-roadway" is constructed, and the expression of the minimum arch thickness of the bearing arch is 
obtained by theoretical calculation. Based on the basic mechanical parameters experiment of bearing arch, the strength of bearing arch is checked.

(3) The results show that the failure of the reconstructed bearing arch is closely related to the overburden load and the thickness of the bearing arch; all the tensile stress and shear stress of the bearing arch increase linearly with the increase of the overburden load and decrease sharply with the increase of the bearing arch thickness, showing a nonlinear relationship.

(4) When the research results are applied to the Wantian coal mine, the deformation of roadway surrounding rock is reduced, and the repair rate is significantly reduced.

\section{Data Availability}

The data used to support the findings of this study are included within the article.

\section{Conflicts of Interest}

All the authors declare that they have no known conflicts of interest that could influence the work reported in this paper.

\section{Acknowledgments}

This research was supported by National Natural Science Foundation of China (Nos. 51764010 and 51874109), Guizhou Province Science and Technology Support Plan Project (No. qiankehezhicheng[2019]2861), New Talent Training Project of Guizhou Institute of Technology (Nos. qiankehepingtairencai [2017]5789-14 and GZLGXM-02), and Guizhou Province Safety Production Major Accident Prevention Key Technology Science and Technology Project (No. guizhou-0004-2017AQ).

\section{References}

[1] X. T. Feng, Rock Mechanics and Engineering Volume 4, Excavation, Support and Monitoring, CRC Press, England, UK, 2016.

[2] H. Kang, "Support technologies for deep and complex roadways in underground coal mines: a review," International Journal of Coal Science \& Technology, vol. 1, no. 3, pp. 261-277, 2014.

[3] J. A. Hudson and X. T. Feng, Rock Engineering Risk, CRC Press, Great Britain, UK, 2015.

[4] J. M. Galvin, Ground Engineering, Springer, Cham, Switzerland, 2016.

[5] W. Yu, B. Pan, F. Zhang, S. Yao, and F. Liu, "Deformation characteristics and determination of optimum supporting time of alteration rock mass in deep mine," KSCE Journal of Civil Engineering, vol. 23, no. 11, pp. 4921-4932, 2019.

[6] M. T. Xu, D. S. Zhang, and W. Zhang, "Deformation and fracture evolution of surrounding rock for shallow underground projects," Electronic Journal of Geotechnical Engineering, vol. 18, pp. 3895-3908, 2013.

[7] Y. L. Xu, R. K. Pan, and H. Zhang, "Investigation of key techniques on floor roadway support under the impacts of superimposed mining: theoretical analysis and field study," Environmental Earth Sciences, vol. 78, p. 15, 2019.

[8] Q. Meng, L. Han, Y. Chen et al., "Influence of dynamic pressure on deep underground soft rock roadway support and its application," International Journal of Mining Science and Technology, vol. 26, no. 5, pp. 903-912, 2016.

[9] Q. Meng, L. Han, Y. Xiao, H. Li, S. Wen, and J. Zhang, "Numerical simulation study of the failure evolution process and failure mode of surrounding rock in deep soft rock roadways," International Journal of Mining Science and Technology, vol. 26, no. 2, pp. 209-221, 2016.

[10] H. Wang, Y. Jiang, S. Xue et al., "Assessment of excavation damaged zone around roadways under dynamic pressure induced by an active mining process," International Journal of Rock Mechanics and Mining Sciences, vol. 77, pp. 265-277, 2015.

[11] J. Tian and S. Gao, "Deformation and failure study of surrounding rocks of dynamic pressure roadways in deep mines," Mining Science and Technology (China), vol. 20, no. 6, pp. 850-854, 2010.

[12] H. Yan and F. L. He, "A new cable truss support system for coal roadways affected by dynamic pressure," International Journal of Mining Science and Technology, vol. 22, no. 5, pp. 613-617, 2012.

[13] W.-J. Wang, L.-Q. Luo, W.-J. Yu, H. Wu, Y.-S. Qu, and Y. S. Qu, "Study of dynamic pressure roadway supporting scheme under condition of thick composite roof," Journal of Coal Science and Engineering (China), vol. 19, no. 2, pp. 119-125, 2013.

[14] J. Zhang, L. Liu, X. Yan, and Y. Li, "Asymmetrical support technology for dynamic pressure roadway: a case study from guotun coal mine in China," Geotechnical and Geological Engineering, vol. 37, no. 2, pp. 823-832, 2019.

[15] X. Yang, C. Liu, Y. Ji, X. Zhang, and S. Wang, "Research on roof cutting and pressure releasing technology of directional fracture blasting in dynamic pressure roadway," Geotechnical and Geological Engineering, vol. 37, no. 3, pp. 1555-1567, 2019.

[16] J. Zuo, J. Wang, and Y. Jiang, "Macro/meso failure behavior of surrounding rock in deep roadway and its control technology," International Journal of Coal Science \& Technology, vol. 6, no. 3, pp. 301-319, 2019.

[17] J. Zuo, Z. Wang, H. Zhou, J. Pei, and J. Liu, "Failure behavior of a rock-coal-rock combined body with a weak coal interlayer," International Journal of Mining Science and Technology, vol. 23, no. 6, pp. 907-912, 2013.

[18] G. Wu, W. Chen, S. Jia et al., "Deformation characteristics of a roadway in steeply inclined formations and its improved support," International Journal of Rock Mechanics and Mining Sciences, vol. 130, Article ID 104324, 2020.

[19] G. Wu, S. Jia, W. Chen, J. Yuan, H. Yu, and W. Zhao, "An anchorage experimental study on supporting a roadway in steeply inclined geological formations," Tunnelling and Underground Space Technology, vol. 82, pp. 125-134, 2018.

[20] H. Zhang, J. Cao, and M. Tu, "Floor stress evolution laws and its effect on stability of floor roadway," International Journal of Mining Science and Technology, vol. 23, no. 5, pp. 631-636, 2013.

[21] S. R. Xie, M. M. Gao, D. D. Chen et al., "Stability influence factors analysis and construction of a deep beam anchorage structure in roadway roof," International Journal of Mining Science and Technology, vol. 28, no. 3, pp. 445-451, 2018.

[22] S. Xie, E. Li, S. Li, J. Wang, C. He, and Y. Yang, "Surrounding rock control mechanism of deep coal roadways and its 
application," International Journal of Mining Science and Technology, vol. 25, no. 3, pp. 429-434, 2015.

[23] Z. Zhang, M. Deng, J. Bai, X. Yu, Q. Wu, and L. Jiang, "Strain energy evolution and conversion under triaxial unloading confining pressure tests due to gob-side entry retained," International Journal of Rock Mechanics and Mining Sciences, vol. 126, Article ID 104184, 2020.

[24] Z. Zhang, M. Deng, X. Wang, W. Yu, F. Zhang, and V. D. Dao, "Field and numerical investigations on the lower coal seam entry failure analysis under the remnant pillar," Engineering Failure Analysis, vol. 115, Article ID 104638, 2020.

[25] Z. Zhang, J. Bai, Y. Chen, and S. Yan, "An innovative approach for gob-side entry retaining in highly gassy fullymechanized longwall top-coal caving," International Journal of Rock Mechanics and Mining Sciences, vol. 80, pp. 1-11, 2015.

[26] G. S. Wu, W. J. Yu, J. P. Zuo, C. Y. Li, J. H. Li, and S. H. Du, "Experimental investigation on rockburst behavior of the rock-coal-bolt specimen under different stress conditions," Scientific Reports, vol. 10, p. 1, 2020.

[27] W. Yu and K. Li, "Deformation mechanism and control technology of surrounding rock in the deep-buried large-span chamber," Geofluids, vol. 2020, Article ID 8881319, 22 pages, 2020.

[28] G. Wu, W. Yu, J. Zuo, and S. Du, "Experimental and theoretical investigation on mechanisms performance of the rockcoal-bolt (RCB) composite system," International Journal of Mining Science and Technology, vol. 30, no. 6, pp. 759-768, 2020.

[29] W. J. Yu, G. S. Wu, B. Pan, Q. H. Wu, and Z. Liao, "Experimental investigation of the mechanical properties of sandstone-coal-bolt specimens with different angles under conventional triaxial compression," International Journal of Geomechanics, vol. 7556, 10 pages, 2020.

[30] B. X. Huang, N. Zhang, H. W. Jing et al., "Large deformation theory of rheology and structural instability of the surrounding rock in deep mining roadway," Journal of China Coal Society, vol. 45, no. 03, pp. 911-926, 2020.

[31] D. Zhu, Y. Wu, Z. Liu, X. Dong, and J. Yu, "Failure mechanism and safety control strategy for laminated roof of widespan roadway," Engineering Failure Analysis, vol. 111, Article ID 104489, 2020.

[32] R. Yang, Y. Li, D. Guo, L. Yao, T. Yang, and T. Li, "Failure mechanism and control technology of water-immersed roadway in high-stress and soft rock in a deep mine," International Journal of Mining Science and Technology, vol. 27, no. 2, pp. 245-252, 2017.

[33] R. S. Yang, Y. L. Li, D. M. Guo et al., "Deformation reasons and support technology of deep and high-stress soft rock roadway," Journal of Mining and Safety Engineering, vol. 34, no. 6, pp. 1035-1041, 2017.

[34] M. Kanji, M. C. He, and L. R. Sousa, Soft Rock Mechanics and Engineering, Springer, Chem, Switzerland, 2020.

[35] X. T. Feng, Rock Characterisation, Modelling and Engineering Design Methods, CRC Press, Boca Raton, FL, USA, 2013.

[36] H. W. Liu, Concise Materials Mechanics, Higher Education Press, Beijing, China, 2008. 